\title{
Clinical value of procalcitonin for suspected noso- comial bloodstream infection
}

Joo Kyoung Cha ${ }^{1}$, Ki Hwan Kwon ${ }^{1}$, Seung Joo Byun ${ }^{1}$, Soo Ryeong Ryoo ${ }^{1}$, Jeong Hyeon Lee ${ }^{1}$, Jae-Woo Chung ${ }^{2}$, Hee Jin $\mathrm{Huh}^{2}$, Seok Lae Chae' ${ }^{2}$, and Seong Yeon Park ${ }^{1}$

Departments of ${ }^{1}$ Internal Medicine and ${ }^{2}$ Laboratory Medicine, Dongguk University Ilsan Hospital, Goyang, Korea
Background/Aims: Procalcitonin (PCT) may prove to be a useful marker to exclude or predict bloodstream infection (BSI). However, the ability of PCT levels to differentiate BSI from non-BSI episodes has not been evaluated in nosocomial BSI.

Methods: We retrospectively reviewed the medical records of patients $\geq 18$ years of age with suspected BSI that developed more than 48 hours after admission.

Results: Of the 785 included patients, 105 (13.4\%) had BSI episodes and 680 (86.6\%) had non-BSI episodes. The median serum PCT level was elevated in patients with BSI as compared with those without BSI ( $0.65 \mathrm{ng} / \mathrm{mL}$ vs. $0.22 \mathrm{ng} / \mathrm{mL}, p=0.001$ ). The optimal PCT cut-off value of BSI was $0.27 \mathrm{ng} / \mathrm{mL}$, with a corresponding sensitivity of $74.6 \%$ (95\% confidence interval [CI], $66.4 \%$ to $81.7 \%$ ) and a specificity of $56.5 \%$ (95\% CI, $52.7 \%$ to $60.2 \%$ ). The area under curve of PCT (0.692) was significantly larger than that of C-reactive protein (CRP; 0.526) or white blood cell (WBC) count (0.518). However, at the optimal cut-off value, PCT failed to predict BSI in 28 of 105 cases $(26.7 \%)$. The PCT level was significantly higher in patients with an eGFR $<60 \mathrm{~mL} / \mathrm{min} / 1.73 \mathrm{~m}^{2}$ than in those with an eGFR $\geq 60 \mathrm{~mL} / \mathrm{min} / 1.73 \mathrm{~m}^{2}$ (o.68 vs. $0.17, p=0.01)$.

Conclusions: PCT was more useful for predicting nosocomial BSI than CRP or WBC count. However, the diagnostic accuracy of predicting BSI remains inadequate. Thus, PCT is not recommended as a single diagnostic tool to avoid taking blood cultures in the nosocomial setting.

Keywords: Procalcitonin; Nosocomial bloodstream infection; Renal function

\section{INTRODUCTION}

Bloodstream infection (BSI) in hospitalized patients is a common and deadly problem. Between $0.5 \%$ and $1.3 \%$ of patients develop BSI during hospitalization [1]. Inhospital mortality estimates among patients with BSI vary between $30 \%$ and $40 \%[2,3]$. Nosocomial BSI is associated with significantly higher mortality rates than community-onset BSI [4-6]. Early administration of effective antimicrobial therapy to patients with BSI has repeatedly been shown to improve mortality in patients with community-acquired and nosocomial BSI [3,7-9]. Therefore, early diagnosis and appropriate treatment is important especially in patients with nosocomial BSI.

Accurate and timely diagnosis of BSI remains challenging to both clinicians and laboratories. The most specific diagnostic modality for BSI is blood culture; however, it usually takes more than 24 hours to obtain results [10]. Many indirect diagnostic modalities have been used to indicate suspected BSI, including fever, 
white blood cell (WBC) count, and C-reactive protein (CRP) level. However, these approaches have poor sensitivity and specificity. More accurate diagnostic tools are needed [11-13].

Elevation in serum procalcitonin (PCT) levels above normal values in patients with sepsis and other clinically significant bacterial infections was first described approximately 25 years ago [14]. PCT level is not elevated in viral infections. PCT has recently been proposed as a useful marker to rule out BSI in the emergency department and to guide antimicrobial therapy in patients hospitalized for community-acquired BSI [8,15,16]. Patients with community-onset BSI have been reported to have higher PCT levels as compared to those with nosocomial BSI [4]. Although mortality is much higher for patients with nosocomial BSI, PCT has not yet been studied in a large nosocomial BSI patient population. Accordingly, we investigated the usefulness of PCT as a diagnostic marker in patients with suspected nosocomial BSI, and assessed the relationship between PCT and renal function.

\section{METHODS}

\section{Patients and population}

We retrospectively reviewed medical records taken from January 2013 to November 2014 in Dongguk University Ilsan Hospital. Patients fulfilling the criteria of systemic inflammatory response (SIRS) with positive peripheral blood cultures were enrolled by clinicians 48 hours after admission. SIRS was defined in patients with two or more of the following conditions: (1) fever (oral temperature $\left.>38^{\circ} \mathrm{C}\right)$ or hypothermia $\left(<36^{\circ} \mathrm{C}\right) ;(2)$ tachypnea $(>24$ breaths/min); (3) tachycardia (heart rate $>90$ beats $/ \mathrm{min}$ ); and (4) leukocytosis $(>12,000 / \mu \mathrm{L})$, leukopenia $(<4,000 /$ $\mu \mathrm{L})$, or $>10 \%$ bands $[17]$. We excluded patients under 18 years of age. This study was approved by the Ethics Review Board of Dongguk University Ilsan Hospital, Korea (2015-110). The need for informed consent was waived because of the retrospective and observational nature of this study.

Basic characteristics, medical history, laboratory data including WBC count, CRP, PCT, and serum creatinine level were reviewed. Estimated glomerular filtration rate (eGFR) was determined by the Chronic Kidney Disease
Epidemiology Collaboration (CKD-EPI) formula [18]. Records were obtained from the previous administration of antibiotics at the time of blood culture in patients with positive blood cultures.

\section{Laboratory examinations}

We performed two or more blood cultures and a PCT test concomitantly on all enrolled patients with SIRS. If the results of the blood culture were positive, the microorganisms were identified and recorded. Blood cultures utilized the BACTEC FX automated system (BD, Sparks, MD, USA). Microorganisms were identified using standard procedures. Antimicrobial susceptibility tests were performed using a Phonenix automated system (BD). Blood samples were obtained from each patient such that samples fulfilled the SIRS criteria and blood cultures and levels of serum PCT and CRP were obtained at the first blood sample obtained for culture. CRP and PCT were tested using a Cobas e602 apparatus (Roche Diagnostics, Mannheim, Germany). The analytical reportable range of the PCT assay was 0.02 to $100 \mathrm{ng} / \mathrm{mL}$. A BSI episode was defined as a positive blood culture with appropriate clinical correlation. Coagulase-negative staphylococci, Bacillus species, Corynebacteria that were isolated in only one blood culture were considered contaminants $[15,19,20]$. Contaminants and negative blood cultures were defined as non-BSI episodes.

\section{Statistical analyses}

Statistical analyses were performed with IBM SPSS version 20 (IBM Co., Armonk, NY, USA). Demographic data, PCT level, CRP, WBC count, renal function, and patient outcomes were compared between the BSI episode and non-BSI episode groups by chi-square test or Mann-Whitney Utest. We plotted the receiver operating characteristic curves of PCT, CRP, WBC level, and the diagnostic accuracy of assessed by area under receiver operating characteristic curves (AUCs). The optimal cutoff value of PCT was identified by maximizing the AUC.

\section{RESULTS}

A total of 814 patients were identified during the study period. Of these, 163 patients displayed positive blood cultures. Among them, 29 cases were regarded as con- 
tamination and 29 patients were already receiving antimicrobial treatment before blood culture. We excluded 58 patients from the BSI group. Thus, 105 patients were allocated to the BSI group and 680 patients were allocat-

Table 1. Characteristics of patients with blood stream infections

\begin{tabular}{lc}
\hline Characteristic & Patients $(\mathrm{n}=105)$ \\
\hline Age, yr & $71(58-79)$ \\
Male sex & $45(57.1)$ \\
McCabe Jackson criteria & \\
\hline Nonfatal & $46(43.8)$ \\
\hline Ultimately fatal & $59(56.2)$ \\
\hline Rapidly fatal disease & $0(0)$ \\
\hline Charlson comorbidity index & $3(2-6)$ \\
\hline Underlying disease & \\
\hline Solid tumor & $47(44.8)$ \\
\hline Neurologic disease & $38(36.2)$ \\
\hline Diabetes mellitus & $36(34.3)$ \\
\hline Chronic kidney disease & $20(19.0)$ \\
\hline Chronic lung disease & $14(13.3)$ \\
\hline Liver cirrhosis & $13(12.4)$ \\
\hline Heart disease & $11(10.4)$ \\
\hline Portal of entry & $17(15.2)$ \\
\hline Respiratory infection & $58(4.8)$ \\
\hline Unknown primary & $54(40.3)$ \\
\hline Gastrointestinal infection & $20(19.0)$ \\
\hline Genitourinary infection & $18(17.9)$ \\
\hline Catheter related blood stream infection & $16.2)$ \\
\hline Mevere sepsis or septic shock & \\
\hline
\end{tabular}

Values are presented as median (interquartile range) or number (\%). ed to the non-BSI group.

The underlying disease and origin of infection of the 105 patients in the BSI group are presented in Table 1. The median age of the study patients was 71 years (interquartile range [IQR], 58 to 79). The median Charlson comorbidity index was 3 (IQR, 2 to 6 ) and 47 patients (44.8\%) had solid tumors, while 28 patients $(26.7 \%)$ had respiratory infections. The baseline characteristics of each group are presented in Table 2. WBC count was not elevated in the BSI group compared to the non-BSI group. In contrast, elevation was evident in the median level of PCT ( $0.65 \mathrm{ng} / \mathrm{mL}$ vs. $0.22 \mathrm{ng} / \mathrm{mL}, p=0.001$ ). Table 3 presents the identification data of the isolated microorganisms. In the BSI group, gram-positive bacteria, gram-negative bacteria, and fungi were isolated from 44 (32.8\%), 48 (35.8\%), and nine patients (6.7\%), respectively. Four patients (3.0\%) had multiple types of isolated bacteria.

Table 4 presents comparative data of PCT, CRP, WBC count stratified by the isolated microorganisms. A statistical difference was evident between gram-negative bacteria and gram-positive bacteria (0.90 [IQR, 0.32 to 4.09 ] vs. 0.44 [IQR, 0.16 to 1.83 ], $p=0.01$ ).

We compared the AUC of PCT, CRP, and WBC count to determine diagnostic accuracy. The AUCs of PCT, CRP, and WBC count were $0.69,0.53$, and 0.52, respectively (Fig. 1). Table 5 presents data concerning the number of cases under the cut-off value, sensitivity, specificity, positive predictive value (PPV), and negative predictive value (NPV) for eight PCT cut-off values. The optimal cut-off value was $0.27 \mathrm{ng} / \mathrm{mL}$. The sensitivity, specificity, PPV, and NPV of the optimal cut-off value ( $0.27 \mathrm{ng} / \mathrm{mL})$

Table 2. Baseline characteristics of the study population in relation to the presence of bloodstream infection

\begin{tabular}{lccc}
\hline Characteristic & Bloodstream infection group $(\mathrm{n}=105)$ & Non-bloodstream infection group $(\mathrm{n}=680)$ & $p$ value \\
\hline Age, $\mathrm{yr}$ & $71.0(58.0-79.0)$ & $70.0(56.0-78.0)$ & 0.16 \\
Male sex & $45(42.8)$ & $368(54.1)$ & 0.03 \\
Creatinine, $\mathrm{mg} / \mathrm{dL}$ & $0.81(0.64-1.35)$ & $0.73(0.56-1.12)$ & 0.87 \\
$\mathrm{eGFR}, \mathrm{mL} / \mathrm{min} / 1.73 \mathrm{~m}^{2}$ & $78.0(41.5-98.4)$ & $89.0(56.0-107.0)$ & 0.01 \\
$\mathrm{PCT}, \mathrm{ng} / \mathrm{mL}$ & $0.65(0.23-2.76)$ & $0.22(0.10-0.70)$ & 0.001 \\
$\mathrm{CRP}, \mathrm{mg} / \mathrm{dL}$ & $5.44(2.02-9.73)$ & $4.59(1.79-9.36)$ & 0.30 \\
WBC count, $/ \mu \mathrm{L}$ & $10,180(5,535-14,730)$ & $9,795(6,788-13,060)$ & 0.25 \\
30-Day mortality & $26(24.8)$ & $48(7.1)$ & $<0.01$ \\
\hline
\end{tabular}

Values are presented as median (interquartile range) or number (\%).

eGFR, estimated glomerular filtration rate; PCT, procalcitonin; CRP, C-reactive protein; WBC, white blood cell. 
were $74.6 \%, 56.5 \%, 25.3 \%$, and $91.9 \%$, respectively. At the time of blood culture sampling, PCT was $<0.1 \mathrm{ng} / \mathrm{mL}$ in seven patients with BSI. PCT was $<0.27 \mathrm{ng} / \mathrm{mL}$ in 28 patients with BSI.

The PCT level was higher in patients with renal insufficiency than in those with normal renal function, as shown in Table 6 . The PCT level was significantly higher in patients with an eGFR $<60 \mathrm{~mL} / \mathrm{min} / 1.73 \mathrm{~m}^{2}$ than in those with an eGFR $\geq 60 \mathrm{~mL} / \mathrm{min} / 1.73 \mathrm{~m}^{2}$ (o.68 [IQR, 0.28 to 2.58 ] vs. 0.17 [IQR, 0.09 to 0.49 ], $p=0.01$ ). There

Table 3. Microorganisms isolated from blood culture

\begin{tabular}{lc}
\hline Microorganism & Isolates \\
\hline Gram-positive bacteria & $44(32.8)$ \\
Staphylococcus aureus & 25 \\
Streptococcus species & 1 \\
Enterococcus species & 9 \\
\hline Other gram-positive bacteria & 9 \\
Gram-negative bacteria & $48(35.8)$ \\
\hline Escherichia coli & 16 \\
\hline Klebsiella species & 13 \\
\hline Acinetobacter species & 8 \\
\hline Pseudomonas aeruginosa & 3 \\
\hline Other gram-negative bacteria & 8 \\
\hline Fungi & $9(6.7)$ \\
\hline Candida albicans & 3 \\
\hline Other Candida species & 6 \\
Multiple microbes & $4(3.0)$ \\
Contaminant bacteria & $29(21.6)$ \\
\hline Coagulase-negative staphylococci & 23 \\
Bacillus species & 3 \\
\hline Other contaminant bacteria & 3 \\
\hline
\end{tabular}

Values are presented as number (\%). was no statistically significant difference in PCT levels between patients with eGFR $<30$ and $30 \leq \mathrm{eGFR}<60$ $\mathrm{mL} / \mathrm{min} / 1.73 \mathrm{~m}^{2}$.

\section{DISCUSSION}

Our study demonstrates a higher PCT level in patients with nosocomial BSI, and shows that an elevated PCT level was more useful for predicting nosocomial BSI than were CRP or WBC count. However, BSI could not be excluded, even if the PCT level was low (0.1 ng/mL). In addition, PCT was significantly correlated with eGFR,

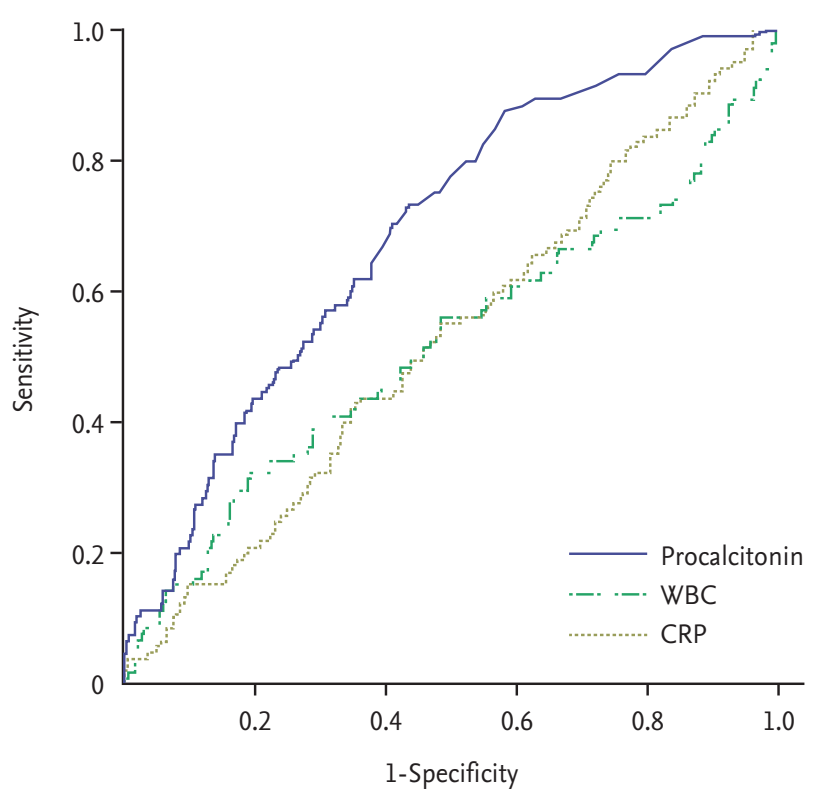

Figure 1. Receiver operating characteristic curves of procalcitonin (PCT), C-reactive protein (CRP), and white blood cell (WBC) count. PCT, CRP, and WBC had areas under the curve of $0.692,0.526$, and 0.518 , respectively.

Table 4. Comparisons of biochemical data from 785 blood tests according to blood culture results

\begin{tabular}{lcclcccc}
\hline \multirow{2}{*}{ Variable } & \multicolumn{2}{c}{ Non-bloodstream infection } & & \multicolumn{4}{c}{ Bloodstream infection } \\
\cline { 2 - 3 } & $\begin{array}{c}\text { Negative } \\
(\mathrm{n}=651)\end{array}$ & $\begin{array}{c}\text { Contamination } \\
(\mathrm{n}=29)\end{array}$ & & $\begin{array}{c}\text { Gram-positive } \\
(\mathrm{n}=44)\end{array}$ & $\begin{array}{c}\text { Gram-negative } \\
(\mathrm{n}=48)\end{array}$ & $\begin{array}{c}\text { Multiple } \\
\text { microbes }(\mathrm{n}=4)\end{array}$ & $\begin{array}{c}\text { Fungi } \\
(\mathrm{n}=9)\end{array}$ \\
\hline PCT, $\mathrm{ng} / \mathrm{mL}$ & $0.21(0.10-0.70)$ & $0.26(0.09-0.61)$ & & $0.44(0.16-1.83)$ & $0.90(0.32-4.09)$ & $0.24(0.12-0.49)$ & $1.01(0.34-2.74)$ \\
CRP, $\mathrm{mg} / \mathrm{dL}$ & $4.67(1.81-9.48)$ & $2.93(1.22-8.13)$ & & $5.92(2.19-10.22)$ & $4.97(1.58-9.30)$ & $3.31(1.24-8.56)$ & $5.44(4.10-11.30)$ \\
WBC count, $/ \mu \mathrm{L}$ & 9,820 & 9,160 & & 10,950 & 9,850 & 8,470 & 9,870 \\
& $(6,780-13,060)$ & $(6,780-11,245)$ & & $(8,020-16,480)$ & $(5,000-13,555)$ & $(3,490-14,447)$ & $(4,765-17,840)$ \\
\hline
\end{tabular}

Values are presented as median (interquartile range).

PCT, procalcitonin; CRP, C-reactive protein; WBC, white blood cell. 
and the optimum cut-off value of PCT for predicting a nosocomial BSI increased along with the deterioration of renal function.

Hoenigl et al. [21] reported a PCT sensitivity of 70\% and $60 \%$ for community-acquired and nosocomial BSI, respectively. However, the authors could not demonstrate positive or NPV owing to limited study population. Previous studies reported a significantly lower PCT level in patients with nosocomial BSI than in those with community-acquired BSI [21,22]. The significantly higher levels of PCT in patients with community-onset BSI might derive from a time delay between the onset of the first symptoms and drawing of blood for laboratory analysis [23]. Other suggestions include the contributions of devices and interventions [22]. Thus, the diagnostic value of PCT might be different between community-acquired BSI and nosocomial BSI.

PCT was superior to CRP and WBC in predicting nosocomial BSI, but its diagnostic accuracy remained modest (AUC, o.69). The optimal cut-off value of PCT was $0.27 \mathrm{ng} / \mathrm{mL}$. However, even at the lowest evaluated cutoff value of $0.1 \mathrm{ng} / \mathrm{mL}$, PCT could not predict BSI in $6 \%$ of cases, and the optimal cut-off value of PCT could not predict BSI in $26 \%$ of cases. This finding is consistent with a previous report [21]. Most previous studies including on community-onset BSI concluded that a low

Table 5. Sensitivity, specificity, PPV, and NPV of serum procalcitonin at different cut-off values of PCT

\begin{tabular}{lccccc}
\hline $\begin{array}{l}\text { Cut-off value of } \\
\text { PCT, ng/mL }\end{array}$ & $\begin{array}{c}\text { No. of cases } \\
\text { under the cut-off value }\end{array}$ & $\begin{array}{c}\text { Sensitivity, \% } \\
(95 \% \text { CI })\end{array}$ & $\begin{array}{c}\text { Specificity, \% } \\
(95 \% \text { CI })\end{array}$ & $\begin{array}{c}\text { PPV, \% } \\
(95 \% \text { CI })\end{array}$ & $\begin{array}{c}\text { NPV, \% } \\
(95 \% ~ C I)\end{array}$ \\
\hline 0.10 & $7 / 105$ & $93.3(86.8-97.3)$ & $24.4(21.2-27.8)$ & $16.0(13.2-19.2)$ & $95.9(91.8-98.3)$ \\
0.27 & $28 / 105$ & $74.6(66.4-81.7)$ & $56.5(52.7-60.2)$ & $25.3(21.1-29.8)$ & $91.9(88.8-94.3)$ \\
0.40 & $43 / 105$ & $61.2(52.4-69.5)$ & $65.7(62.0-69.3)$ & $26.0(21.3-31.3)$ & $89.6(86.6-92.1)$ \\
0.50 & $46 / 105$ & $56.2(46.2-65.9)$ & $69.6(65.9-73.0)$ & $22.2(17.3-27.7)$ & $91.1(88.3-93.4)$ \\
0.60 & $50 / 105$ & $52.4(42.0-64.2)$ & $72.5(69.0-75.8)$ & $22.9(17.6-28.5)$ & $90.8(88.0-93.1)$ \\
0.90 & $58 / 105$ & $45.5(37.0-54.4)$ & $78.8(75.6-81.8)$ & $29.8(23.6-36.5)$ & $88.0(85.2-90.5)$ \\
2.0 & $72 / 105$ & $31.4(22.7-41.2)$ & $86.8(84.0-89.2)$ & $26.8(19.2-35.6)$ & $89.1(86.5-91.4)$ \\
5.0 & $105 / 105$ & $14.3(8.2-22.5)$ & $93.5(91.4-95.3)$ & $25.4(15.0-38.4)$ & $87.6(85.0-90.0)$ \\
\hline
\end{tabular}

PCT, procalcitonin; CI, confidence interval; PPV, positive predictive value; NPV, negative predictive value.

Table 6. Procalcitonin value for predicting positive blood culture according to renal function

\begin{tabular}{lccc}
\hline Characteristic & eGFR $\geq 60(\mathrm{n}=564)$ & $30 \leq \mathrm{eGFR}<60(\mathrm{n}=113)$ & $\mathrm{eGFR}<30(\mathrm{n}=108)$ \\
\hline Creatinine, $\mathrm{mg} / \mathrm{dL}$ & $0.64(0.51-0.79)$ & $1.34(1.16-1.56)$ & $3.73(2.55-5.58)$ \\
eGFR, $\mathrm{mL} / \mathrm{min} / 1.73 \mathrm{~m}^{2}$ & $98.3(85.0-111.0)$ & $44.0(38.5-52.5)$ & $13.0(8.0-21.0)$ \\
PCT, ng/mL & $0.17(0.09-0.49)$ & $0.38(0.16-1.79)$ & $0.99(0.45-3.21)$ \\
Optimal cut-off value of PCT, ng/mL & 0.12 & 0.84 & 1.71 \\
Sensitivity, \% & $85.3(74.6-92.7)$ & $61.1(35.7-82.7)$ & $63.16(38.4-83.7)$ \\
Specificity, \% & $38.5(34.2-43.0)$ & $86.0(80.8-90.3)$ & $69.7(59.0-79.0)$ \\
PPV, \% & $16.0(12.4-20.2)$ & $26.2(13.9-42.0)$ & $30.8(17.0-47.6)$ \\
NPV, \% & $95.0(91.0-97.6)$ & $96.4(92.8-98.6)$ & $89.9(80.2-95.8)$ \\
AUC & 0.691 & 0.705 & 0.661 \\
CRP, mg/dL & $4.31(1.63-9.35)$ & $5.02(2.05-8.83)$ & $6.41(2.91-12.14)$ \\
WBC count, $/ \mu \mathrm{L}$ & $9,510(6,432-13,055)$ & $10,480(7,510-13,680)$ & $10,590(7,630-13,825)$ \\
30-Day mortality & $35(16.1)$ & $19(16.8)$ & $20(18.5)$ \\
\hline
\end{tabular}

Values are presented as median (interquartile range) or number (\%).

eGFR, estimated glomerular filtration rate; PCT, procalcitonin; PPV, positive predictive value; NPV, negative predictive value; AUC, area under curve; CRP, C-reactive protein; WBC, white blood cell. 
PCT level can be used to rule out the presence of BSI $[8,15,16,20,24,25]$. In one such study, a PCT cut-off value $\leq$ $0.1 \mathrm{ng} / \mathrm{mL}$ seemed to be a useful marker to rule out bacteremia in the emergency department in patients with community-acquired BSI [15]. Two meta-analyses on the diagnostic accuracy of PCT for BSI also suggested that low PCT was effective at excluding BSI $[24,25]$. Hoeboer et al. [24] reported that a PCT cut-off value of $0.5 \mathrm{ng} / \mathrm{mL}$ corresponded with a $71 \%$ to $89 \%$ sensitivity and $95 \%$ to $98 \%$ NPV for different hospital settings. In the present study, a $0.5 \mathrm{ng} / \mathrm{mL}$ PCT cut-off value produced a sensitivity of $55.2 \%$ and NPV of $88.8 \%$ (Table 5). Even at the lowest cut-off value (0.1 ng/mL), NPV was only $94.5 \%$. Although PCT was elevated in patients with nosocomial BSI, its diagnostic accuracy as a biomarker remained inadequate, as reported for intensive care unit patients [26]. Several factors may explain this poor performance. First, PCT increases with a 24- to 48 -hour time lag after infection onset, which reduces the effectiveness of crude PCT measured when BSI is suspected [27,28]. Second, PCT remains elevated for up to several weeks after infection. Because hospitalized patients may be subject to several bacterial insults during their hospital stay, PCT may still be elevated due to previous episodes, thereby lowering its ability to detect a new BSI. Lastly, many conditions associated with hospital stay (profound circulatory failure, major surgery, trauma, pancreatitis, etc.) trigger systemic release of inflammatory mediators responsible for a nonspecific PCT increase [29-32]. Therefore, an approach where blood cultures are guided only by PCT cannot be recommended in the nosocomial setting.

We found that the PCT level was especially high in cases involving gram-negative bacteria rather than gram-positive bacteria. Gram-negative bacteria tend to induce higher levels of blood PCT compared with gram-positive bacteria [25,33]. This may reflect different interactions of gram-positive and gram-negative bacteria with host cells, involving lipoteichoic acids or lipopolysaccharide [34]. In particular, gram-positive bacteria activate the Toll-like receptor 2 (TLR2) pathway [35,36], whereas gram-negative bacteria are involved in the TLR4 pathway [37], resulting in different production of inflammatory cytokines, which ultimately stimulate ubiquitous transcription of calcitonin-mRNA and release of PCT from multiple tissues.
The mechanism of metabolism of PCT is not wellknown; some studies have reported elevation of PCT in patients with impaired renal function [38-41]. A significant correlation between PCT and eGFR has been demonstrated $[16,41]$. Similarly, in our study, impaired renal function influenced the PCT level (Table 6). The cause of PCT elevation in patients with renal dysfunction could be impaired renal or hepatic elimination or increased production. Peripheral blood mononuclear cells release more PCT in patients with impaired renal function and in those receiving renal replacement therapy [42]. In addition, patients with severe renal dysfunction often show evidence of a systemic inflammatory response, which leads to PCT production [38]. In the present study, the PCT level tended to increase as eGFR fell, although there was no significant statistical difference between the $30 \leq \mathrm{eGFR}<60 \mathrm{~mL} / \mathrm{min} / 1.73 \mathrm{~m}^{2}$ group and the eGFR $<30 \mathrm{~mL} / \mathrm{min} / 1.73 \mathrm{~m}^{2}$ group. Sitter et al. [43] proposed that loss of renal function does not affect the PCT; however, they set the normal PCT value $<0.5 \mathrm{ng} / \mathrm{mL}$, which is higher than our cut-off values of $0.84 \mathrm{ng} / \mathrm{mL}$ in the $30 \leq \mathrm{eGFR}<60 \mathrm{~mL} / \mathrm{min} / 1.73 \mathrm{~m}^{2}$ group and $1.71 \mathrm{ng} / \mathrm{mL}$ in the eGFR $<30 \mathrm{~mL} / \mathrm{min} / 1.73 \mathrm{~m}^{2}$ group.

Our study has some limitations. It is a retrospective single center study done on a selected population. There may have been some selection bias because of the study's retrospective design. The patient population might be heterogenous because of various hospitalization settings, including wards and intensive care units. Second, unexpected factors that could affect PCT levels were not concurrently analyzed in this study. It is well established that such conditions as profound circulatory failure, major surgery, trauma, and pancreatitis diminish the diagnostic value of PCT [29-32]. Third, our study design established the diagnostic value of PCT for predict nosocomial BSI, so blood culture-confirmed infections included only a BSI group. There is a possibility that patients with a local infection with a negative blood culture might be included in the non-BSI group [44]. Another factor to consider is the possibility of patients receiving antibiotic treatment before blood cultures were obtained, which would result in false negative blood culture results in individuals with high PCT levels, in turn reducing the PPV of PCT for predicting BSI. However, when we investigated the administration of antibiotics before blood collection for culture in the 
group of patients with BSI, the level of PCT was not different between those who had received prior antibiotic administration and those who had not.

In conclusion, PCT level was higher in patients with nosocomial BSI and was more useful for predicting nosocomial BSI than was CRP or WBC count. However, even at the lowest cut-off value, PCT could not rule out nosocomial BSI. Therefore, an approach for blood cultures guided by PCT only does not seem reasonable.

\section{KEY MESSAGE}

1. Procalcitonin (PCT) might be a useful marker to exclude or predict bloodstream infection (BSI). However, the ability of PCT levels to differentiate BSI from non-BSI episodes has not been evaluated in nosocomial BSI.

2. PCT level was higher in patients with nosocomial BSI and was more useful for predicting nosocomial BSI than C-reactive protein or white blood cell count.

3. However, even at the lowest cut-off value, PCT could not rule out nosocomial BSI. Therefore, an approach for blood cultures guided by PCT only does not seem reasonable.

\section{Conflict of interest}

No potential conflict of interest relevant to this article was reported.

\section{REFERENCES}

1. Pittet D, Wenzel RP. Nosocomial bloodstream infections: secular trends in rates, mortality, and contribution to total hospital deaths. Arch Intern Med 1995;155:1177-1184.

2. Parrillo JE. Pathogenetic mechanisms of septic shock. N Engl J Med 1993;328:1471-1477.

3. Nakamura A, Wada H, Ikejiri M, et al. Efficacy of procalcitonin in the early diagnosis of bacterial infections in a critical care unit. Shock 2009;31:586-591.

4. Hoenigl M, Wagner J, Raggam RB, et al. Characteristics of hospital-acquired and community-onset blood stream infections, South-East Austria. PLoS One 2014;9:e104702.

5. Diekema DJ, Beekmann SE, Chapin KC, Morel KA, Mun- son E, Doern GV. Epidemiology and outcome of nosocomial and community-onset bloodstream infection. J Clin Microbiol 2003;41:3655-3660.

6. Kollef MH, Zilberberg MD, Shorr AF, et al. Epidemiology, microbiology and outcomes of healthcare-associated and community-acquired bacteremia: a multicenter cohort study. J Infect 2011;62:130-135.

7. Leibovici L, Shraga I, Drucker M, Konigsberger H, Samra $\mathrm{Z}$, Pitlik SD. The benefit of appropriate empirical antibiotic treatment in patients with bloodstream infection. J Intern Med 1998;244:379-386.

8. Goncalves-Pereira J, Povoa PR, Lobo C, Carneiro AH. Bloodstream infections as a marker of community-acquired sepsis severity: results from the Portuguese community-acquired sepsis study (SACiUCI study). Clin Microbiol Infect 2013;19:242-248.

9. Jensen JU, Heslet L, Jensen TH, Espersen K, Steffensen P, Tvede M. Procalcitonin increase in early identification of critically ill patients at high risk of mortality. Crit Care Med 2006;34:2596-2602.

10. Mitaka C. Clinical laboratory differentiation of infectious versus non-infectious systemic inflammatory response syndrome. Clin Chim Acta 2005;351:17-29.

11. Bates DW, Sands K, Miller E, et al. Predicting bacteremia in patients with sepsis syndrome: Academic Medical Center Consortium Sepsis Project Working Group. J Infect Dis 1997;176:1538-1551.

12. Jaimes F, Arango C, Ruiz G, et al. Predicting bacteremia at the bedside. Clin Infect Dis 2004;38:357-362.

13. Clyne B, Olshaker JS. The C-reactive protein. J Emerg Med 1999;17:1019-1025.

14. Assicot M, Gendrel D, Carsin H, Raymond J, Guilbaud J, Bohuon C. High serum procalcitonin concentrations in patients with sepsis and infection. Lancet 1993;341:515-518.

15. Riedel S, Melendez JH, An AT, Rosenbaum JE, Zenilman JM. Procalcitonin as a marker for the detection of bacteremia and sepsis in the emergency department. Am J Clin Pathol 2011;135:182-189.

16. Hattori $T$, Nishiyama $H$, Kato $H$, et al. Clinical value of procalcitonin for patients with suspected bloodstream infection. Am J Clin Pathol 2014;141:43-51.

17. Levy MM, Fink MP, Marshall JC, et al. 2001 SCCM/ESICM/ACCP/ATS/SIS International Sepsis Definitions Conference. Crit Care Med 2003;31:1250-1256.

18. Stevens LA, Coresh J, Greene T, Levey AS. Assessing kidney function: measured and estimated glomerular filtra- 
tion rate. N Engl J Med 2006;354:2473-2483.

19. Liaudat S, Dayer E, Praz G, Bille J, Troillet N. Usefulness of procalcitonin serum level for the diagnosis of bacteremia. Eur J Clin Microbiol Infect Dis 2001;20:524-527.

20. Chirouze C, Schuhmacher H, Rabaud C, et al. Low serum procalcitonin level accurately predicts the absence of bacteremia in adult patients with acute fever. Clin Infect Dis 2002;35:156-161.

21. Hoenigl M, Raggam RB, Wagner J, et al. Procalcitonin fails to predict bacteremia in SIRS patients: a cohort study. Int J Clin Pract 2014;68:1278-1281.

22. Groeneveld AB, Hack CE. The role of the innate immune response in hospital- versus community-acquired infection in febrile medical patients. Int J Infect Dis 2008;12:660-670.

23. Laupland KB, Kibsey PC, Galbraith JC. Community-onset bloodstream infection during the 'after hours' is not associated with an increased risk for death. Can J Infect Dis Med Microbiol 2012;23:170-172.

24. Hoeboer SH, van der Geest PJ, Nieboer D, Groeneveld AB. The diagnostic accuracy of procalcitonin for bacteraemia: a systematic review and meta-analysis. Clin Microbiol Infect 2015;21:474-481.

25. Oussalah A, Ferrand J, Filhine-Tresarrieu P, et al. Diagnostic accuracy of procalcitonin for predicting blood culture results in patients with suspected bloodstream infection: an observational study of 35,343 consecutive patients (a STROBE-compliant article). Medicine (Baltimore) 2015;94:e1774.

26. Brechot N, Hekimian G, Chastre J, Luyt CE. Procalcitonin to guide antibiotic therapy in the ICU. Int J Antimicrob Agents 2015;46 Suppl 1:S19-S24.

27. Meisner M, Brunkhorst FM, Reith HB, Schmidt J, Lestin HG, Reinhart K. Clinical experiences with a new semiquantitative solid phase immunoassay for rapid measurement of procalcitonin. Clin Chem Lab Med 2000;38:989995.

28. Wagner KE, Martinez JM, Vath SD, et al. Early immunoneutralization of calcitonin precursors attenuates the adverse physiologic response to sepsis in pigs. Crit Care Med 2002;30:2313-2321.

29. Mimoz O, Benoist JF, Edouard AR, Assicot M, Bohuon C, Samii K. Procalcitonin and C-reactive protein during the early posttraumatic systemic inflammatory response syndrome. Intensive Care Med 1998;24:185-188.

30. Carsin H, Assicot M, Feger F, et al. Evolution and signifi- cance of circulating procalcitonin levels compared with IL-6, TNF alpha and endotoxin levels early after thermal injury. Burns 1997;23:218-224.

31. Kylanpaa-Back ML, Takala A, Kemppainen EA, et al. Procalcitonin, soluble interleukin-2 receptor, and soluble E-selectin in predicting the severity of acute pancreatitis. Crit Care Med 2001;29:63-69.

32. Meisner M, Tschaikowsky K, Hutzler A, Schick C, Schuttler J. Postoperative plasma concentrations of procalcitonin after different types of surgery. Intensive Care Med 1998;24:680-684.

33. Charles PE, Ladoire S, Aho S, et al. Serum procalcitonin elevation in critically ill patients at the onset of bacteremia caused by either gram negative or gram positive bacteria. BMC Infect Dis 2008;8:38.

34. Kumar S, Ingle H, Prasad DV, Kumar H. Recognition of bacterial infection by innate immune sensors. Crit Rev Microbiol 2013;39:229-246.

35. Echchannaoui H, Frei K, Schnell C, Leib SL, Zimmerli W, Landmann R. Toll-like receptor 2-deficient mice are highly susceptible to Streptococcus pneumoniae meningitis because of reduced bacterial clearing and enhanced inflammation. J Infect Dis 2002;186:798-806.

36. Takeuchi O, Hoshino K, Kawai T, et al. Differential roles of TLR2 and TLR4 in recognition of gram-negative and gram-positive bacterial cell wall components. Immunity 1999;11:443-451.

37. Poltorak A, He X, Smirnova I, et al. Defective LPS signaling in $\mathrm{C}_{3} \mathrm{H} / \mathrm{HeJ}$ and $\mathrm{C}_{57} \mathrm{BL} / 10 \mathrm{OSCr}$ mice: mutations in Tlr4 gene. Science 1998;282:2085-2088.

38. Meisner M, Lohs T, Huettemann E, Schmidt J, Hueller $\mathrm{M}$, Reinhart K. The plasma elimination rate and urinary secretion of procalcitonin in patients with normal and impaired renal function. Eur J Anaesthesiol 2001;18:79-87.

39. Amour J, Birenbaum A, Langeron $O$, et al. Influence of renal dysfunction on the accuracy of procalcitonin for the diagnosis of postoperative infection after vascular surgery. Crit Care Med 2008;36:1147-1154.

40. Dahaba AA, Rehak PH, List WF. Procalcitonin and C-reactive protein plasma concentrations in nonseptic uremic patients undergoing hemodialysis. Intensive Care Med 2003;29:579-583.

41. Park JH, Kim DH, Jang HR, et al. Clinical relevance of procalcitonin and C-reactive protein as infection markers in renal impairment: a cross-sectional study. Crit Care 2014;18:640. 
42. Herget-Rosenthal S, Klein T, Marggraf G, et al. Modulation and source of procalcitonin in reduced renal function and renal replacement therapy. Scand J Immunol 2005;61:180-186.

43. Sitter T, Schmidt M, Schneider S, Schiffl H. Differential diagnosis of bacterial infection and inflammatory re- sponse in kidney diseases using procalcitonin. J Nephrol 2002;15:297-301.

44. Marra AR, Edmond MB, Forbes BA, Wenzel RP, Bearman GM. Time to blood culture positivity as a predictor of clinical outcome of Staphylococcus aureus bloodstream infection. J Clin Microbiol 2006;44:1342-1346. 